\title{
Analysis of a New Vibratory Conveyor Allowing for a Sudden Stopping of the Transport
}

\author{
Piotr CZUBAK, Antoni LIS
}

\begin{abstract}
The new solutions of a vibratory conveyor utilised for transporting - with variable velocities - loose materials or objects of small dimensions, were analysed in this study. This vibratory conveyor has a possibility of immediate suspension of the feed material flow without the necessity of the drive switching off. Up to the present, this type of solution was realised by means of an expensive electromagnetic exciter. The conveyor analysed in this paper is induced to vibration by a significantly cheaper and often employed electro-vibrator. Such solution has not been applied for suspension of transport so far in the industry, while it is essential at discontinuous operations of the conveyor, especially at the feed dosage. This solution allows to design cheap production lines within which the conveyor will realise not only continuous transport. Values of amplitudes of the trough and applied eliminator in dependence of the excitation frequency were analytically determined. The results were confirmed by the simulation analysis of the device. The whole model of the conveyor together with the loose feed was investigated by the simulation analysis of the feed transport velocity in dependence of the excitation frequency of the system. The obtained results are very satisfactory and provide the basis for further investigation of the conveyor in a laboratory set-up.
\end{abstract}

Keywords: dynamic reaction; Frahm's eliminator; non-stationary state; vibrations; vibratory conveyor

\section{INTRODUCTION}

The subject of the analysis is the new solution of the vibratory conveyor of a variable transport velocity with the possibility of sudden stopping of the feed material flow, without the necessity of the drive switch off. This conveyor is used for transporting loose materials or objects of small dimensions [1].

Very often there is the necessity to stop conveyor operations in the production line. In the case of belt conveyors this is not difficult, while in the case of vibratory conveyors their switching off is connected with the necessity of the system to pass through successive resonance zones during the machine start-up and coast-up. Vibratory conveyors-in non-stationary states-often transport materials with a higher velocity than in the steady state, which means that a sudden stop of the feed material flow from the conveyor is difficult. Therefore there is a scarce number of solutions, and in consequence publications, concerning vibratory conveyors driven by rotating inertial vibrators, are able to stop the feed flow. However, there are known industrial solutions of conveyors driven by electromagnetic inertial excitation e.g. US 6253908 [2], in which controlling the transport velocity by variable excitations is relatively easy, but such excitation systems are twice as expensive.

There are also known vibratory conveyors (US 5615763 [3] or US 6598734 [4]), equipped with two or more vibrators suspended to the trough, which electric motors are driving shafts with an unbalanced mass mounted to them, forcing vibrations at an angle oriented to the vertical plane, passing through the longitudinal axis of the trough. In dependence of the required transport velocity the control system is respectively disphasing inertial vibrators, changing the excitation value and - in consequence - the amplitude and direction of the trough vibrations causing the change of the feed transport velocity. However, in such a solution it is impossible to suddenly stop the transport.

A similar solution, in which the disphasing of vibrators is performed by means of various mechanical joints, is patented (US 5979640 [5]), but such systems are usually of a low durability.
Another kind of conveyor (US 3064357) [6] is equipped with a system of sensors connected to the control system, which by analysing the feed layer thickness and transport velocity, knows the amount of the transported material and can switch off the machine in the proper moment. The difficulty in this case is caused by the feed amount transported during the coasting time, when machine vibrations are much higher than in the steady state.

There are also vibratory conveyors, (description of US 7222750 [7]), equipped with devices closing the feed flow onto the trough or the closing is on the side of the feed flow (US 4247019 [8]). However, systems of closing the trough transporting loose materials based on the mechanical system - in which parts of this system are mutually sliding - do not work in vibratory conveyors, because it is difficult to start the device before particles of the transported material will enter into it.

\section{STRUCTURE OF THE ANALYSED CONVEYOR}

The new vibratory conveyor submitted for patenting $[9,10]$ is presented in Fig. 1. This conveyor consists of a classic trough (1) elastically supported (2) on a rigid base in a horizontal placement. It is equipped with a system of two counter running vibrators (3) suspended to the trough at $\beta$ angle. In the steady state vibrators are synchronised and counter rotating giving the resultant rectilinear force $P_{0}=2 m_{\mathrm{e}} \sin (\omega t)$, passing through the mass system centre of the trough as well as through its suspension system centre. Motors driving inertial vibrators are equipped with the inverter (4) by means of which the control system is able to control the rotating velocity of electrovibrators (3).

The auxiliary mass $(5)$ is connected on its suspension (6) to the main mass (1). Its aim is the elimination of trough vibrations at the proper control of the excitation frequency of vibrators, in accordance with the Frahm's eliminator rule [11]. When the trough vibrations stop, the feed transport also stops (7). 


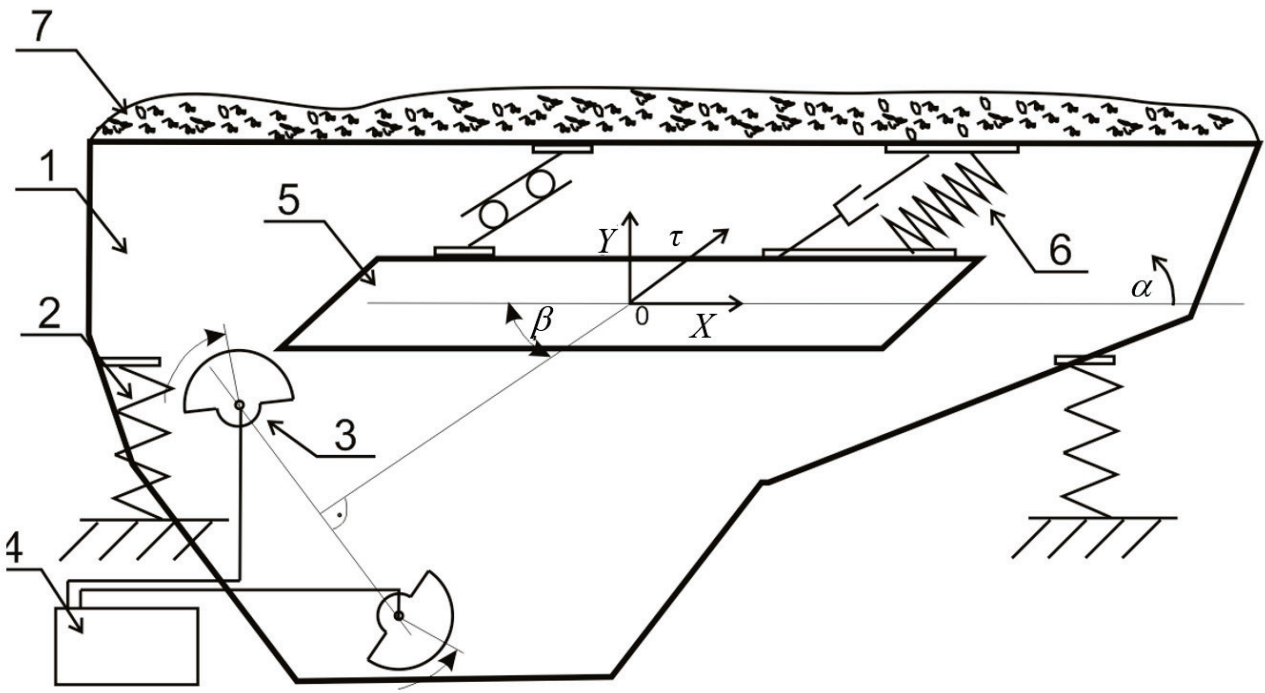

Figure 1 Schematic presentation of the conveyor being the subject of the invention

\section{PRINCIPLE OF THE CONVEYOR OPERATIONS}

The concept predicts the possibility of transporting material with a velocity typical for the given machine class, when the excitation frequency is significantly below the partial frequency of the additional mass of the eliminator (5) at its suspension (6). In order to stop the feed flow the excitation frequency should be changed in such a way as to obtain a value equal to the natural partial frequency of the mass (5) on its suspension. When constants $m_{\mathrm{e}}$ and $k_{\tau}$ are selected in such a way as to have partial frequency equal to the excitation frequency $\omega$.

$\omega=\sqrt{\frac{k}{m}}$

the vibrations of mass $m_{\mathrm{e}}$ are steadying and the force in spring $k_{\tau}$ counter balances the excitation force - in case of a lack or a small damping in the system $P=m_{1} \mathrm{e}_{1} \sin (\omega t)+m_{2} \mathrm{e}_{2} \sin (\omega t)$ damping vibrations of the main mass, i.e. of the trough (1). This effect occurs regardless of the natural frequencies of the basic system. The system of the Frahm's eliminator operates in the antiresonance valley surrounded on both sides by resonance zones and this valley width depends on the ratio of the eliminator mass to the main mass. The stopping of vibrations of the trough, and in consequence the feed transport stopping, can be achieved in a short time. Damping of vibrations is nearly total. It should be emphasised that the feed transport is stopped even at small vibrations of the trough, before their total damping, due to a small coefficient of throw. The advantage of this solution constitutes the possibility of stopping the feed flow without the necessity of switching off the device and - in consequence - without the necessity of the system passage through the resonance zones. This conveyor is very suitable for the accurate dosage of the feed, especially in the mode of the frequent stops of the transport. An additional benefit of this solution is the fact that when the transport is stopped the feed distributes uniformly along the trough. The transport restart occurs when the excitation frequency of unbalanced masses decreases itself to the operating frequency of the conveyor in the steady state. At that time, the vibrations of the mass of the dynamic eliminator (5) will not significantly influence the vibrations of the main mass (1) and the transport will restart.

\section{ANALITICAL INVESTIGATIONS}

The system presented in Fig. 1 has four degrees of freedom related to coordinates $x, y, \tau$ and $\beta$ - respectively, and two degrees of freedom related to electrovibrators. At the assumption that the trough suspension stiffness in $x$ and $y$ direction is identical and that the direction of the excitation force originated from electrovibrators passes through the centre of gravity as well as through the suspension system centre, the conveyor system can be reduced to the system presented in Fig. 2 [12, 13].

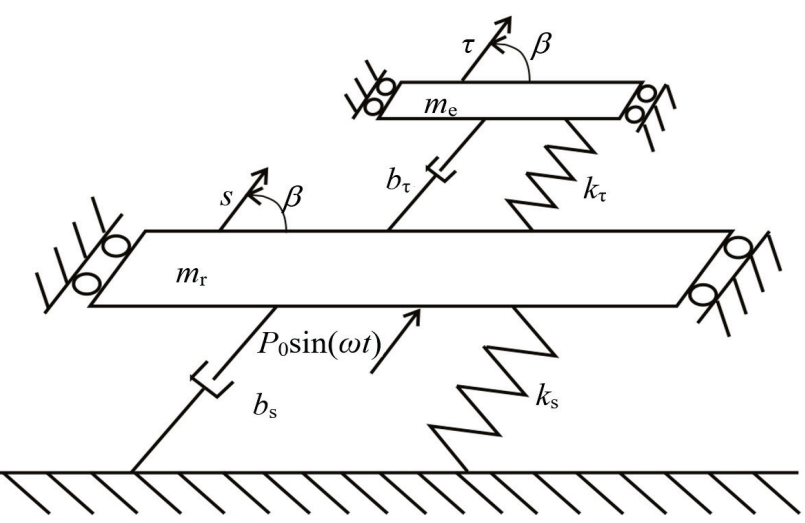

Figure 2 Simplified scheme of the conveyor presented in Fig. 1

The mathematical model of the conveyor is then simplified and its analysis is definitely easier.

Equations of the system presented in Fig. 2 are as follows:

$$
\begin{aligned}
& m_{\mathrm{e}} \ddot{\tau}+b_{\tau}(\dot{\tau}-\dot{s})+k_{\tau}(\tau-s)=0 \\
& m_{\mathrm{r}} \ddot{s}-b_{\tau}(\dot{\tau}-\dot{s})+b_{\mathrm{s}} \dot{s}-k_{\tau}(\tau-s)+k_{s} s=P_{0}(t)
\end{aligned}
$$

Assuming monoharmonic excitation in the form:

$P_{0}(t)=m_{\mathrm{e}} \omega^{2} \sin (\omega t)$ 
$m$ - sum of masses of unbalanced vibrators

$e$ - eccentric of the vibrator mass, and limiting to the steady state, the differential equations system can be reduced to the following forms:

$$
\begin{aligned}
& -m_{\mathrm{e}} \omega^{2} T+b_{\tau} I \omega(\underline{T}-\underline{S})+k_{\tau}(\underline{T}-\underline{S})=0 \\
& -m_{\mathrm{r}} \omega^{2} \underline{S}+b_{\tau} I \omega(\underline{S}-\underline{T})+b_{\mathrm{s}} I \omega \underline{S}+k_{\tau}(\underline{S}-\underline{T})+k_{\mathrm{s}} \underline{S}=m_{\mathrm{e}} \omega^{2}
\end{aligned}
$$

where:

$\underline{T}$ - amplitude of the eliminator harmonic motion along coordinate $\tau$,

$\underline{S}$ - amplitude of the trough harmonic motion along coordinate $s$

$\omega$ - circular frequency of the excitation force $P_{0}(t)$
$I$ - imaginary unit,

$m_{\mathrm{r}}$ - mass of the conveyor trough,

$m_{\mathrm{e}}$ - mass of the dynamic eliminator,

$m$ - sum of unbalanced masses of the vibrator,

$e$ - eccentric of the mass $m$,

$k_{\tau}, b_{\tau}$ - sum of elasticity and damping of leaf springs in the working direction $\tau$,

$k_{\mathrm{s}}=2 k_{x}=2 k_{y}$ - coefficient of elasticity of the support system of the vibroinsulating frame,

$b_{\mathrm{s}}=2 b_{x}=2 b_{y}$ - damping coefficient of the support system of the vibroinsulating frame

After solving these equations versus unknowns $T$ and $S$ the complex amplitudes value is obtained:

$$
\begin{aligned}
& \underline{T}=\frac{-m_{\mathrm{e}} \omega^{2}\left(-b_{\tau}^{2} \omega^{2}+k_{\tau}^{2}+2 I k_{\tau} b_{\tau}\right)}{\left(m_{\mathrm{r}} m_{\mathrm{e}} \omega^{4}-m_{\mathrm{r}} \omega^{2}\left(k_{\tau}+k_{\mathrm{s}}\right)-m_{\mathrm{e}} \omega^{2} k_{\tau}+k_{\tau} k_{\mathrm{s}}-b_{\tau} b_{\mathrm{s}} \omega^{2}\right)-I\left(m_{\mathrm{r}} \omega^{3}\left(b_{\tau}+b_{\mathrm{s}}\right)-k_{\tau} b_{\mathrm{s}} \omega+m_{\mathrm{e}} \omega^{3} b_{\tau}-b_{\tau} k_{\mathrm{s}} \omega\right)\left(k_{\tau}+I b_{\tau} w\right)} \\
& \underline{S}=\frac{-m_{\mathrm{e}} \omega^{2}\left(-m_{\mathrm{r}} \omega^{2}+k_{\tau}+I b_{\tau} \omega\right)}{\left(m_{\mathrm{r}} m_{\mathrm{e}} \omega^{4}-m_{\mathrm{r}} \omega^{2}\left(k_{\tau}+k_{\mathrm{s}}\right)-m_{\mathrm{e}} \omega^{2} k_{\tau}+k_{\tau} k_{\mathrm{s}}-b_{\tau} b_{\mathrm{s}} \omega^{2}\right)-I\left(m_{\mathrm{r}} \omega^{3}\left(b_{\tau}+b_{\mathrm{s}}\right)-k_{\tau} b_{\mathrm{s}} \omega+m_{\mathrm{e}} \omega^{3} b_{\tau}-b_{\tau} k_{\mathrm{s}} \omega\right)}
\end{aligned}
$$

Modules of complex values (which are not shown here because of a significant size of such solution) determine the real values of amplitudes.

The above given equations can be used to determine amplitudes of the trough and eliminator vibrations as the excitation frequency function. Fig. 4 presents the dependence of the trough vibrations amplitude in the excitation frequency function, while Fig. 3 presents analogical vibrations of the eliminator for the parameters of the conveyor given in Tab. 1 .

It is seen from these figures that the system is not passing through any resonance zone when the excitation frequency changes from the operational frequency 110 $\mathrm{rad} / \mathrm{s}$ to the frequency causing the feed transport stopping $157 \mathrm{rad} / \mathrm{s}$.

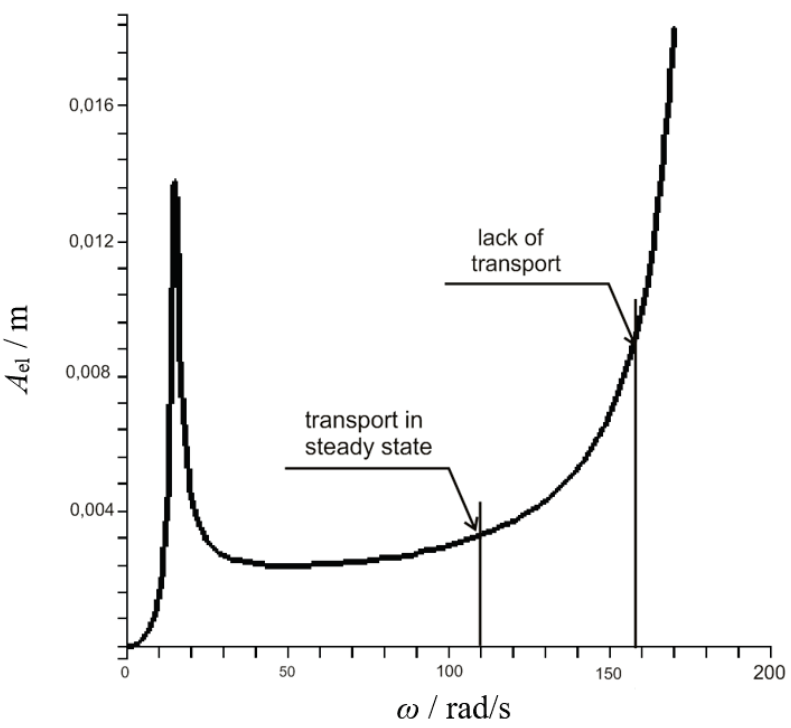

Figure 3 Amplitude of the eliminator vibrations in the motion direction

When the feed transport is stopped the dynamic eliminator operates in the resonance slope related to the second frequency of the system and not in resonance, as it is often erroneously assumed (Fig. 3). In addition, due to infinitely variable change of the amplitude of the trough vibrations between the excitation frequencies 110 and 157 $\mathrm{rad} / \mathrm{s}$ (when the transport stops), it is possible - in a relatively simple way - to control the feed transport velocity from the stop to full velocity. This provides the possibility of accurate dosing of the feed.

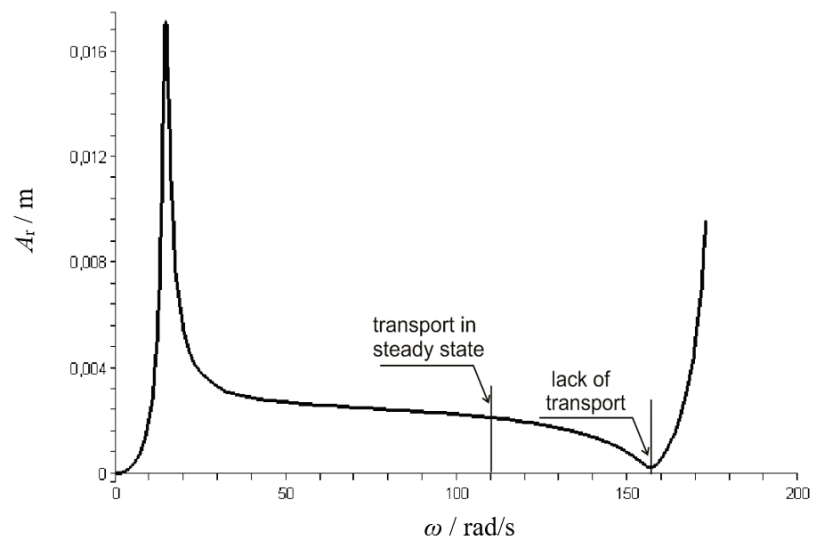

Figure 4 Amplitude of the trough vibrations in the motion direction

\section{SIMULATION INVESTIGATIONS}

On account of a strong dependence of the eliminator efficiency on damping occurring in the system [14, 15], calculations performed without taking into consideration the feed load are burdened with a large error [16, 17]. It can be expected in the case of the analyzed conveyor that the feed will have a smaller influence on the eliminator operations since this eliminator does not have any direct contact with the feed, as it happens in case of resonance conveyors. Nevertheless, further investigations were performed on the model taking into account the feed load (Fig. 5). This provides also the possibility of determining the transport velocity and the width of the zone in which the feed transport decays. 


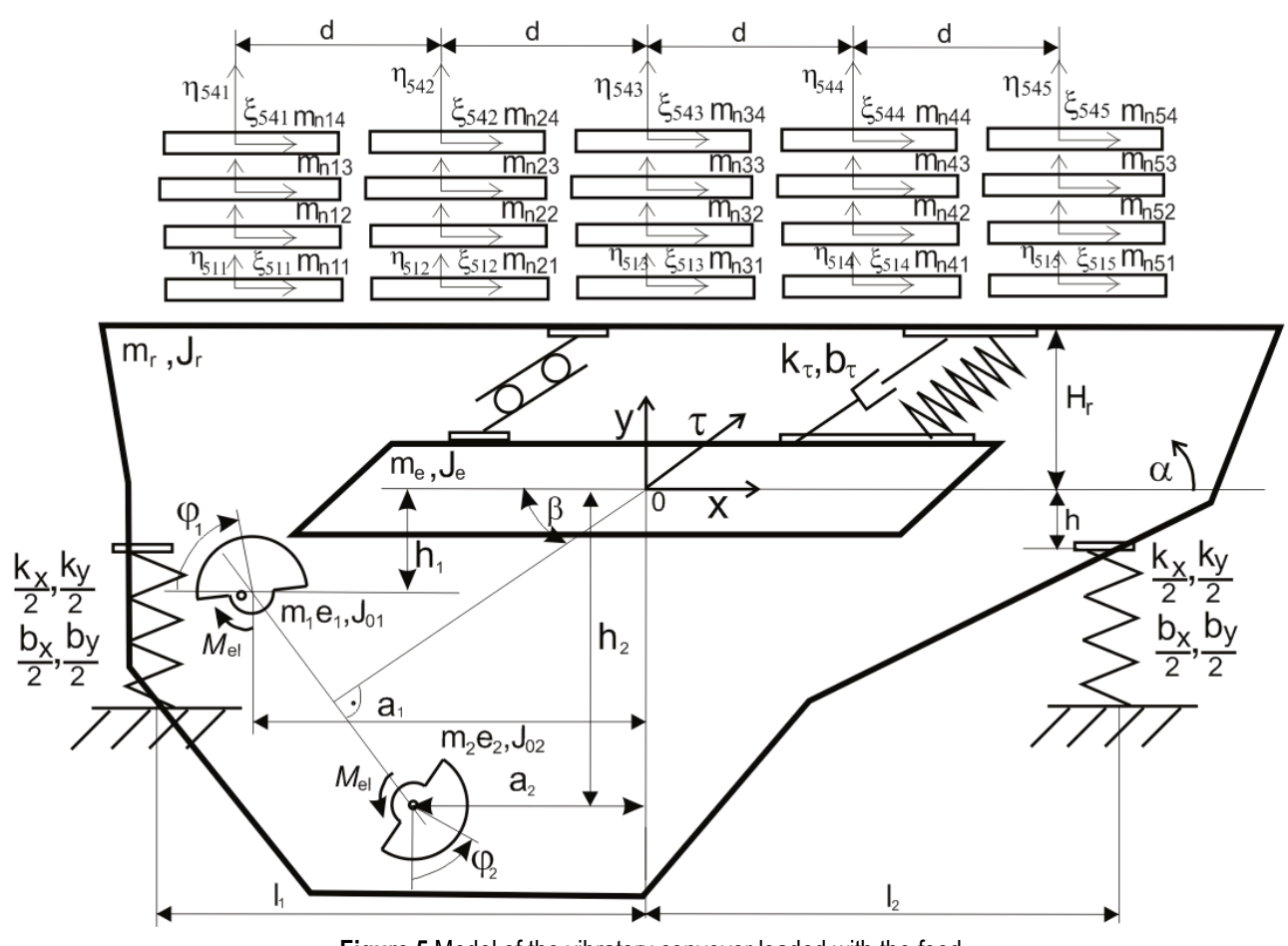

Figure 5 Model of the vibratory conveyor loaded with the feed

The analyzed system consists of two inertial vibrators, excited by induction motors (described by means of a static characteristic). These vibrators are exciting for vibrations a frame suspended on a spiral springs system. The conveyor trough together with the feed $[18,19]$ is suspended on the frame, by means of the leaf springs system allowing for the relative motion of the trough and frame only along $\tau$ axis.

$[\boldsymbol{M}] \cdot[\ddot{\boldsymbol{q}}]=[\boldsymbol{Q}]$

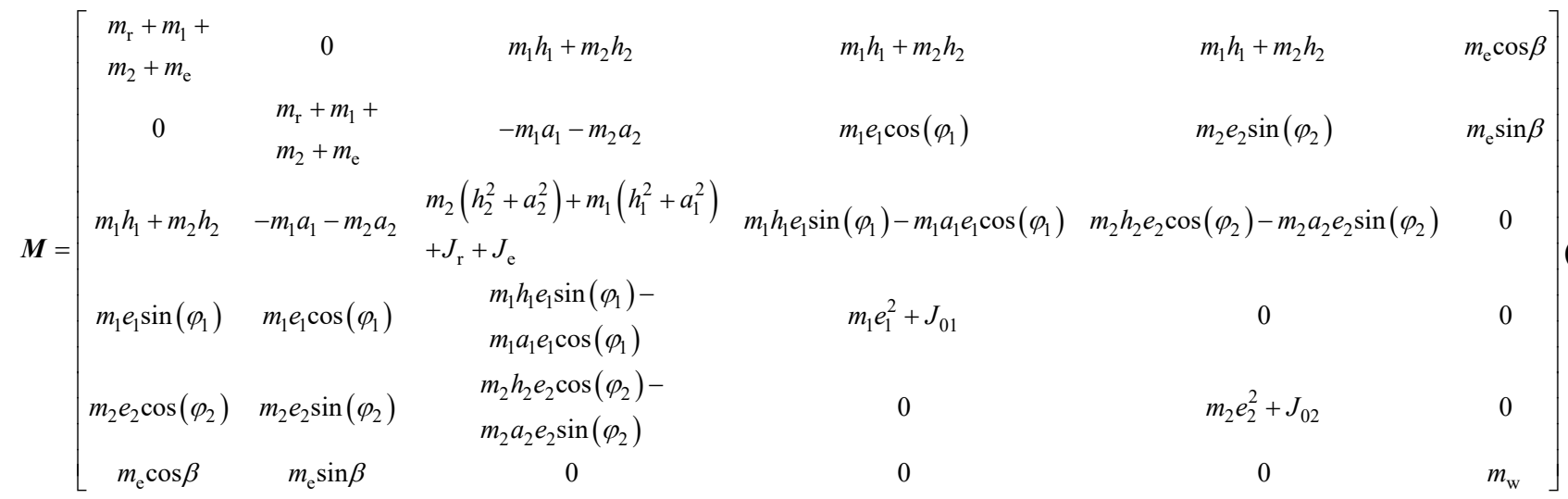

The mathematical model of such a system consists of the matrix Eq. (6) describing the machine motion, Eq. (13) describing the electromagnetic moment of drive motors, Eq. (12) used for determining the motion of successive feed layers and of dependences (10) and (11) describing normal and tangent influences between feed layers as well as between the feed layer and machine body.

$$
\ddot{\boldsymbol{q}}=\left[\begin{array}{llllll}
\ddot{x} & \ddot{y} & \ddot{\beta} & \ddot{\phi}_{1} & \ddot{\phi}_{2} & \ddot{\tau}
\end{array}\right]^{\mathrm{T}}
$$

$$
\boldsymbol{Q}=\left[\begin{array}{c}
m_{2} e_{2} \varphi_{2}^{2} \sin \left(\varphi_{2}\right)-m_{1} e_{1} \varphi_{1}^{2} \sin \left(\varphi_{1}\right)-2 k_{x}(x+h \alpha)-2 b_{x}(x+h \alpha)-T_{1(01)}-T_{1(02)}-T_{1(03)}-T_{1(04)}-T_{1(05)}- \\
-m_{2} e_{2} \varphi_{2}^{2} \sin \left(\varphi_{2}\right)+m_{1} e_{1} \varphi_{1}^{2} \sin \left(\varphi_{1}\right)-k_{y}\left(\mathrm{y}+l_{1} \alpha\right)--b_{y}\left(\mathrm{y}+l_{1} \alpha\right)-b_{y}\left(\mathrm{y}+l_{2} \alpha\right)-F_{1(01)}-F_{1(02)}-F_{1(03)}-F_{1(04)}-F_{1(05)} \\
-b_{y}\left(\mathrm{y}+l_{1} \alpha\right)-b_{y}\left(\mathrm{y}+l_{2} \alpha\right)-F_{1(01)}-F_{1(02)}-F_{1(03)}-F_{1(04)}-F_{1(05)}--m_{1} e_{1} \varphi_{1}^{2} \sin \left(\varphi_{1}\right)-m_{1} e_{1} \varphi_{1}^{2} \sin \left(\varphi_{1}\right)+m_{2} e_{2} \varphi_{2}^{2} \sin \left(\varphi_{2}\right)+m_{2} e_{2} \varphi_{2}^{2} \sin \left(\varphi_{2}\right) \\
-2 k_{x} h^{2} \alpha-2 k_{x} h x-2 b_{x} h x-2 b_{x} h^{2} \alpha-k_{y}\left(\mathrm{y}+l_{1} \alpha\right) l_{1}+k_{y}\left(\mathrm{y}+l_{2} \alpha\right) l_{2} \\
-b_{y}\left(\mathrm{y}+l_{1} \alpha\right) l_{1}+b_{y}\left(\mathrm{y}+l_{2} \alpha\right) l_{2}\left(T_{1(01)}+T_{1(02)}+T_{1(03)}+T_{1(04)}+T_{1(05)}\right) H_{\mathrm{r}}++2 \mathrm{~d} F_{1(01)}+\mathrm{d} F_{1(02)}-\mathrm{d} F_{1(04)}-\mathrm{d} F_{1(05)} \\
M_{e l 1}-b_{s 1} \varphi_{1}^{2} \operatorname{sign}\left(\varphi_{1}\right)-m_{1} g e_{1} \cos \left(\varphi_{1}\right) \\
M_{e l 2}-b_{s 2} \varphi_{2}^{2} \operatorname{sign}\left(\varphi_{2}\right)-m_{2} g e_{2} \cos \left(\varphi_{2}\right)-k_{\tau} \tau-b_{\tau} \tau
\end{array}\right](9)
$$


where:

$\tau$ - dependent coordinate,

$F_{j,(j-1, k)}$ - normal component of the $j$-th layer pressure on $j-1$ in the $k$-th column,

$T_{j,(j-j, k)}$ - tangent component of the $j$-th layer pressure on $j-1$ in the k-th column,

$j$ - indicator $j=0$ of the material layer is related to the machine body,

$k$ - indicator of the column.

When the successive feed layers $j$ and $j-1$ (in the given column) are not in contact, the contact force in the normal $F_{j,(j-1, k)}$ and tangent $T_{j,(j-j, k)}$ direction - between these layers - is equal to zero. Otherwise, the contact force in the normal direction between feed layers $j, k$ and $j-1, k$ (or in case of the first layer: between the layer and trough), is as follows [20]:

$$
\begin{aligned}
& F_{j,(j-1, k)}=\left(\eta_{j-1, k}-\eta_{j, k}\right)^{p} \cdot k \cdot \\
& \left\{1-\frac{1-R^{2}}{2}\left[1-\operatorname{sgn}\left(\eta_{j-1, k}-\eta_{j, k}\right) \cdot \operatorname{sgn}\left(\dot{\eta}_{j-1, k}-\dot{\eta}_{j, k}\right)\right]\right\}
\end{aligned}
$$

and the force originated from friction in the tangent direction:

$$
T_{j,(j-1, k)}=-\mu F_{j,(j-1, k)} S G N\left(\dot{\xi}_{j, k}-\dot{\xi}_{j-1, k}\right)
$$

Equations of motion in directions ( and $\mid$ of individual feed layers, with taking into account the influence of the conveyor on lower feed layers, are of the form:

$$
\begin{aligned}
& m_{n j, k} \ddot{\xi}=T_{j,(j-1, k)}-T_{j+1,(j, k)} \\
& m_{n j, k} \ddot{\eta}=-m_{n j, k} g+F_{j,(j-1, k)}-F_{j+1,(j, k)} \\
& \mathcal{M}_{e l} \frac{2 \mathcal{M}_{u t}\left(\omega_{s s}-\dot{\phi}_{i 1}\right)\left(\omega_{s s}-\omega_{u t}\right)}{\left(\omega_{s s}-\omega_{u t}\right)^{2}+\left(\omega_{s s}-\dot{\phi}_{i}\right)^{2}}
\end{aligned}
$$

$\mathcal{M}_{e l}$ - moment generated by drive motors

$\mathcal{M}_{u t}$ - moment of stall of drive motors,

$\omega_{s s}$ - synchronous frequency of drive motors,

$\omega_{u t}$ - stall frequency of drive motors.

Simulations were performed for the parameters given in Tab. 1.

\section{Table 1 Parameters of the simulated system}

$l_{1}=1 \mathrm{~m} ;$
$l_{2}=1 \mathrm{~m} ;$
$h=0 \mathrm{~m} ;$
$h_{1}=0,4 \mathrm{~m} ;$
$h_{2}=0,8 \mathrm{~m} ;$
$a_{1}=0,8 \mathrm{~m} ;$
$a_{2}=0,4 \mathrm{~m} ;$
$d=0,8 \mathrm{~m} ;$
$H_{r}=0 \mathrm{~m} ;$
$e_{1}=\mathrm{e}_{2}=0,029 \mathrm{~m} ;$
$k_{e}=2464900 \mathrm{~N} / \mathrm{m}$
$k_{x}=k_{y}=100000 \mathrm{~N} / \mathrm{m} ;$
$b_{x}=b_{y}=400 \mathrm{Ns} / \mathrm{m}$
$b_{e}=100 \mathrm{Ns} / \mathrm{m} ;$
$b_{s 1}=b_{s 2}=0,00009-$ coefficient of vibrators bearings resistance $\left(\mathrm{Ns}^{2} / \mathrm{m}\right) ;$
$m_{r}=360 \mathrm{~kg} ;$

$m_{1}=\mathrm{m}_{2}=20 \mathrm{~kg}$;

$m_{e}=100 \mathrm{~kg}$;

$J_{1}=J_{2}=0,01 \mathrm{kgm}^{2}$;

$J_{r}=50 \mathrm{kgm}^{2}$

$J_{e}=30 \mathrm{kgm}^{2}$

$M_{u t}=50 \mathrm{Nm}$

$\omega_{u t}=$ variable $(\mathrm{rad} / \mathrm{s})$

$\omega_{s s}=$ variable $(\mathrm{rad} / \mathrm{s})$

$R=0,13$

$\mu=0,4$;

$k=108 \mathrm{~N} / \mathrm{m}$

\section{RESULTS OF SIMULATION INVESTIGATIONS}

In order to verify the operational correctness of the new solution of the vibratory conveyor several simulations were performed. The example of the waveforms of the trough and feed in the vertical direction as the time function, for the steady state operation of the conveyor during the transport, is given in Fig. 6. It can be seen that at the simulated parameters - the conveyor is in the monostrike system.

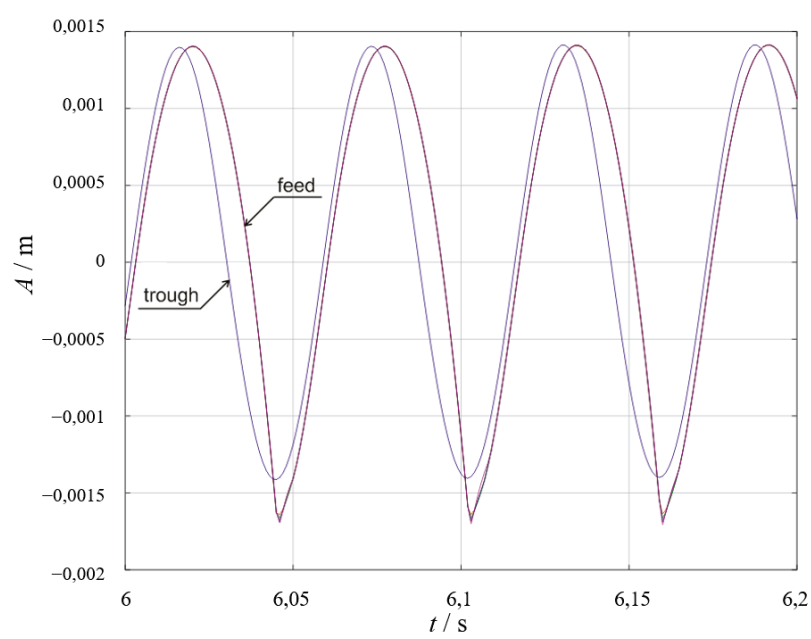

Figure 6 Waveforms of vertical directions of the trough and the feed loaded on it, for the steady state operations of the conveyor

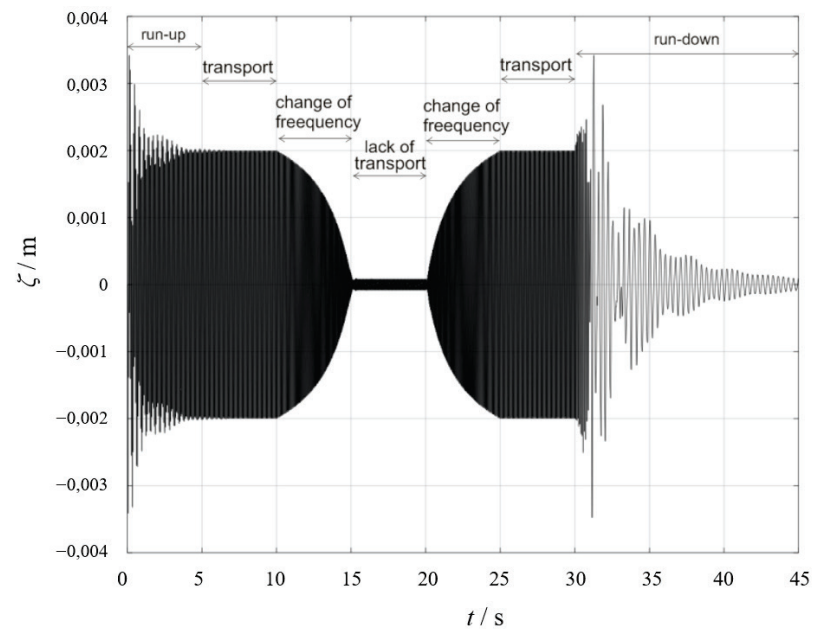

Figure 7 Vibrations of the trough in the motion direction

Fig. 7 presents trough vibrations in the motion direction, while Fig. 8 the transport velocity, for variable excitation, which - for the given simulation - is shown in Fig. 9. After switching on the conveyor obtains the operational frequency in the steady state being equal to 110 $\mathrm{rad} / \mathrm{s}$, at which the transport starts. In between the $10^{\text {th }}$ and 
$15^{\text {th }}$ second the excitation frequency increases up to achieving $157 \mathrm{rad} / \mathrm{s}$, for which the additional mass on its suspension was tuned.

At this frequency the additional mass acts as the Frahm's eliminator, eliminating the trough vibrations in the motion direction, which - in practice - means the stopping of the feed transport. In between the $20^{\text {th }}$ and $25^{\text {th }}$ second the excitation frequency decreases, causing the trough vibrations to increase until they obtain the amplitude of vibrations in the steady state, causing restarting of the transport. After the $30^{\text {th }}$ second the conveyor is switched off and, in successive seconds, passes through the coasting phase.

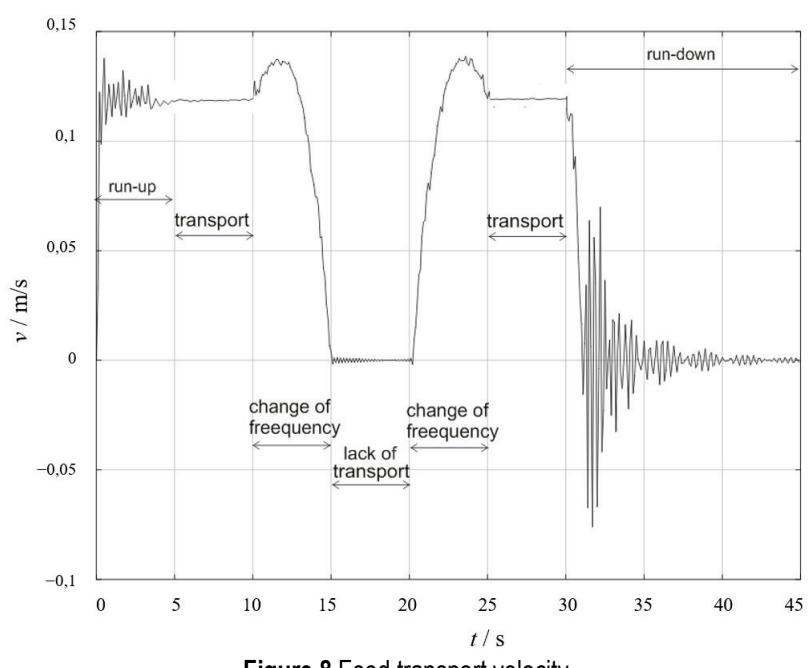

Figure 8 Feed transport velocity

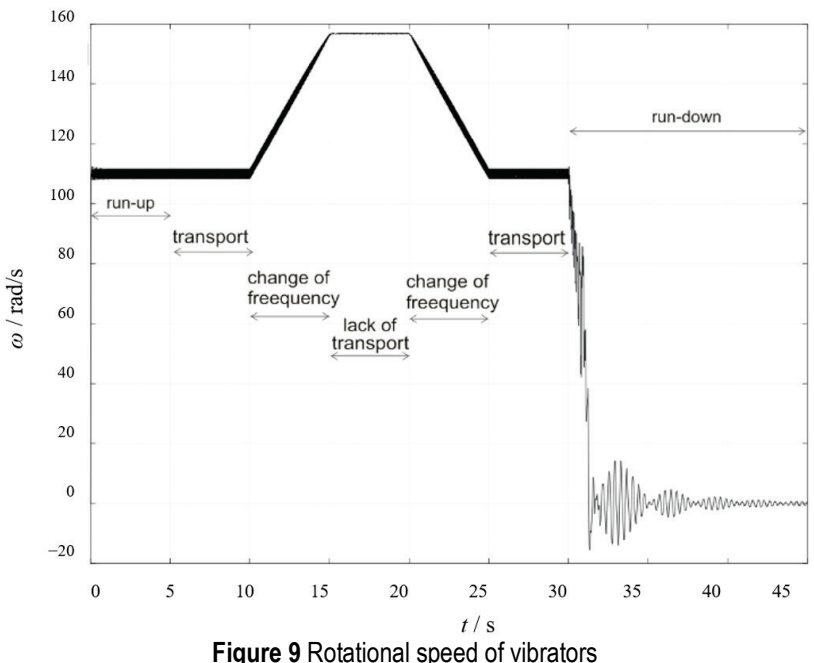

A successive important problem constitutes the width of the antiresonance valley, at which the transport will stop, which means - in practice - determining how accurately condition Eq. (1) must be satisfied to stop the transport.

The trough vibrations amplitude in the working direction as the function of the excitation frequency for quasi steady states, is presented in Fig. 10. It can be seen from the diagram that the transport will stop between 154 and $160 \mathrm{rad} / \mathrm{s}$, a relatively wide range not causing problems with controlling the excitation frequency of conveyors (small trough vibrations during the transport stopping do not cause feed motion because of a low coefficient of throw). The results shown in the diagram in Fig. 10 are analogous to the ones determined earlier from analytical equations (Fig. 4). Moreover, in this case the system passes through the higher number of resonances related to the higher number of degrees of freedom.

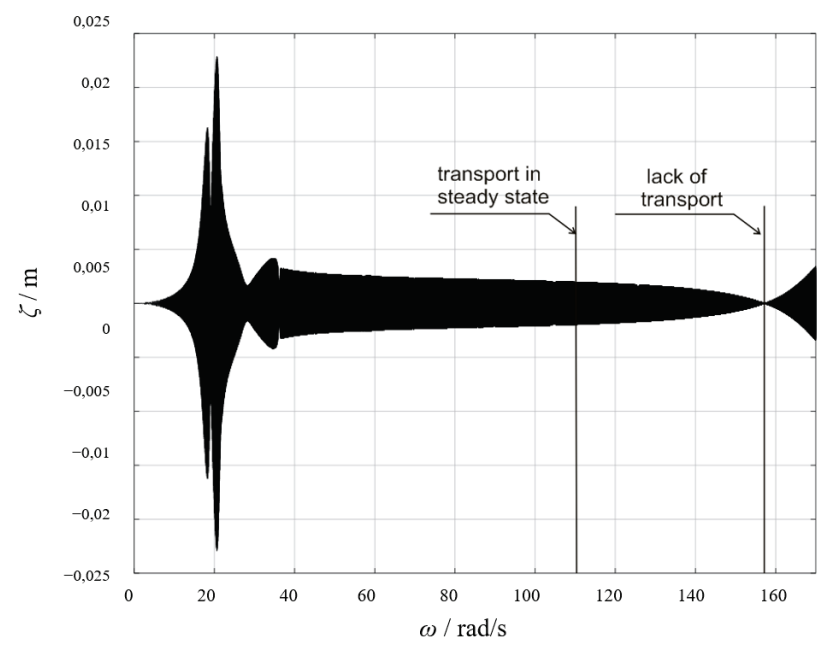

Figure 10 Trough vibrations in the working direction as the function of the excitation frequency of vibrators for quasi steady states

\section{CONCLUSIONS}

Detailed analysis of obtained results allowed for formulating the following conclusions:

The analytical and simulation investigations of the new solution of the conveyor fully confirmed its suitability in production applications. Both operating in the discontinuous mode and continuous material dosage are discussed. Up to the present, conveyors with the electrovibratory drive, which have the possibility of a sudden transport stop, are not common in the industry.

Proposed stop of the transport due to the large width of the antiresonant zone is presented as an easily applicable task. In the tested conveyor the transport can be stopped at the excitation frequency from 154 to $160 \mathrm{rad} / \mathrm{s}$. The width of the antiresonant zone influences the easiness of the feed dosage.

Investigations of the conveyor loaded with feed, indicated that during the transportation it stably operates in the single-stroke mode, while when the transportation is stopped the feed movement decays and its velocity oscillates near zero.

Once the frequency is being retuned between the transportation and stopping stages the system is not passing through any resonance zone, which in case of the electrovibratory drive is unusual.

A drawback of this solution is an insignificant velocity increase of the transport before its decrease at the transport stopping as well as a temporary velocity increase (exceeding the velocity at the stable state) at restarting the transport. These temporary velocity increases can be reduced by the proper control of the excitation frequency.

This type of conveyors is suitable for the application in production lines, e.g. in glass-works, where the feed transport is often discontinuous and the feed amount is very accurately dosed when the furnace is supplied with it. 


\section{Acknowledgements}

They are taken in the framework of the Department of Mechanics and Vibroacoustics. 16.16.130.942

\section{REFERENCES}

[1] Surówka, W., Lis, A., \& Czubak, P. (2018). Analisis of the Author's Solution of the Vibratory Conveyor. Modelowanie Inżynierskie, 68(37), 119-124. http://www.kms.polsl.pl/mi/pelne 37/15 37 68.pdf

[2] Gilman, D. E. (1998). Vibratory conveyor. US Patent No.6253908

[3] Schieber, D. A. (1998). Vibratory conveyor system for adjusting the periodic resultant forces supplied to a conveyor trough. US Patent No.5615763.

[4] Rosenstrom, R. (2002). Vibratory distribution conveyor. US Patent No. 6598734.

[5] Horton, W. A. (1997). Vibrating conveyor drive with continuously adjustable stroke. US Patent No.5979640.

[6] Butters, R. B. (1959). Conveyor speed control by measuring material level. US Patent No.3064357.

[7] Mosca, P. (2004). Transfer and dosing device of pulverulent or granular material contained in a hopper. US Patent No.7222750.

[8] Lerner, B. (1997). Article handling system with dispenser. US Patent No.4247019.

[9] Surówka, W. \& Czubak, P. (2018). Przenośnikwibracyjny. Patent application no. P.425950.

$\mathrm{http} / /$ regserv.uprp.pl/register/application?lng=en\&number= P.425950

[10] Surówka, W. \& Czubak, P. (2018). Przenośnik wibracyjny, zwłaszcza o znacznej dlugości. Patent application no. P.425951.

http://regserv.uprp.pl/register/application?lng=en\&number= P.425951

[11] Frahm, H. (1909). Device for Damping Vibrations of Bodies. US Patent No.989958.

[12] Czubak, P. (2013). Selected problems of the vibratory conveyors dynamics. Kraków: Wydawnictwa AGH. https://www.wydawnictwoagh.pl/pliki/696391998.pdf

[13] Czubak, P. (2011). Equalization of the Transport Velocity in a New Two-Way Vibratory Conveyor. Archives of Civil and Mechanical Engineering, 1(11), 573-586. https://doi.org/10.1016/S1644-9665(12)60102-2

[14] Jiao, C., Liu, J., \& Wang, Q. (2012). Dynamic Analysis of Nonlinear Anti-Resonance Vibration Machine Based on General Finite Element Method. Advanced Materials Research, 443-444, 694-699. https://doi.org/10.4028/www.scientific.net/AMR.443-444.694

[15] Zhao, B. \& Gao, H. (2009). Amplitude Control for a Driving Point Antiresonant Vibrating Screen Based on Fuzzy Selftuning ID Control. Journal of Liaoning Provincial College of Communications.

http://caod.oriprobe.com/articles/16231646/Amplitude_Con trol_for_a_Driving_Point_antiresonant_Vibrating_Screen Ba.htm

[16] Michalczyk, J. \& Czubak, P. (2010). Influence of Collisions with a Feed Material on Cophasal Mutual Synchronisation of Driving Vibrators of Vibratory Machines. Journal of Theoretical and Applied Mechanics, 1(48). http://www.ptmts.org.pl/jtam/index.php/jtam/article/view/v 48n1p155/242

[17] Michalczyk, J. \& Czubak, P. (2010). Influence of the asymmetry of vibrators resistance to motion on the correctness of the vibration distribution on working surfaces of vibratory machines. Archives of Metallurgy and Materials, 55.

http://imim.pl/files/archiwum/Vol1_2010/39.pdf
[18] Bednarski, Ł. \& Michalczyk, J. (2017). Modelling of the working process of vibratory conveyors applied in the metallurgical industry. Archives of Metallurgy and Materials, 2(62), 721-728. https://doi.org/10.1515/amm-2017-0109

[19] Michalczyk, J. \& Cieplok, G. (2006). Model cyfrowy przesiewacza wibracyjnego. Modelowanie Inżynierskie, $32(1)$.

http://www.kms.polsl.pl/mi/pelne_1/michalczyk_cieplok.pd $\mathrm{f}$

[20] Michalczyk, J. (2008). Phenomenon of Force Impulse Restitution in Collision Modelling. Journal of Theoretical and Applied Mechanics, 4(46).

http://www.ptmts.org.pl/jtam/index.php/jtam/article/view/v 46n4p897/392

\section{Contact information:}

Piotr Czubak, DSc, Prof AGH,

AGH - University of Science and Technology,

Faculty of Mechanical Engineering and Robotics

Al. Mickiewicza 30, Building D-1,

30-059 Kraków, Poland

E-mail: czubak@agh.edu.pl

Antoni Lis, PhD student,

AGH - University of Science and Technology,

Faculty of Mechanical Engineering and Robotics,

Al. Mickiewicza 30, Building D-1,

30-059 Kraków, Poland

E-mail: alis@agh.edu.pl 